\section{GENE DELIVERY}

\section{Virus stamping in single cells} Nat. Biotechnol. 36, 81-88 (2018)

In recent years, tissues have gotten more complex. Not really, of course. It's just that molecular analysis has revealed a greater number of cell types in a given tissue like the cerebral cortex in the brain, which plays a key role in memory, language, consciousness, and other mental processes. "Ten years ago, if you asked someone how many types of cells they thought there are in the cortex, you would get an answer of ten or 20," says Botond Roska, director at the Institute of Molecular and Clinical Ophthalmology Basel and group leader at the Friedrich Miescher Institute.

More recent estimates put the number at closer to 100 . That trend has complicated efforts to study tissues. To understand how tissues function and develop, researchers often need to target and query the activity of individual single cells, usually using viruses to deliver genes to alter its function or illuminate its activity. In the brain, for example, researchers may want to map networks of interconnected neurons. One popular technique requires delivery of a fluorescence-producing virus to a specific neuron and watching it spread to connected cells.

The current method delivers DNA encoding a viral receptor to the vicinity of the cell and then applies an electrical field to make the cell membrane more permeable, allowing the DNA to infiltrate. After a few days, once the cell has used the DNA to produce the receptor and display it on its surface, researchers can follow with introduction of the virus, which then only infects the target cell, and then spreads from there. That method is technically complex and time-consuming.

Roska and his colleague Daniel Müller, professor of biophysics at ETH Zürich, developed a simpler technique they call virus stamping, which delivers the virus to the cell surface in a surprisingly low-tech way. Viral particles are first bound to magnetic nanoparticles, and these get loaded into a fine-tipped pipette. When delivering to tissue, a barrier holds the particles in reserve until the pipette reaches the target cell. Then the researcher places a magnet on the exterior of the far side of the animal and releases the barrier. Pulled by the external magnet, the particles travel to the pipette tip where they are held fast against the surface of the cell. "If you push it to the surface, it cannot unbind. These are immensely infective particles," says Roska.

For cell lines or other two-dimensional surfaces, viruses can also be linked to the surface of a blunted pipette. The pipette 'kisses' the target cell, and viruses detach directly on to its surface.

The bond between the viruses and the magnetic nanoparticles is weak enough that the viral particle's interaction with a cell surface receptor is enough to detach the virus from the magnetic particle. Initially, the researchers cooked up a range of complicated solutions for links of just the right strength. "We over-engineered the system. In the end, simplicity is what always wins," says Roska.

\section{Jim Kling}

Published online: 26 February 2018

https://doi.org/10.1038/s41684-018-0013-z

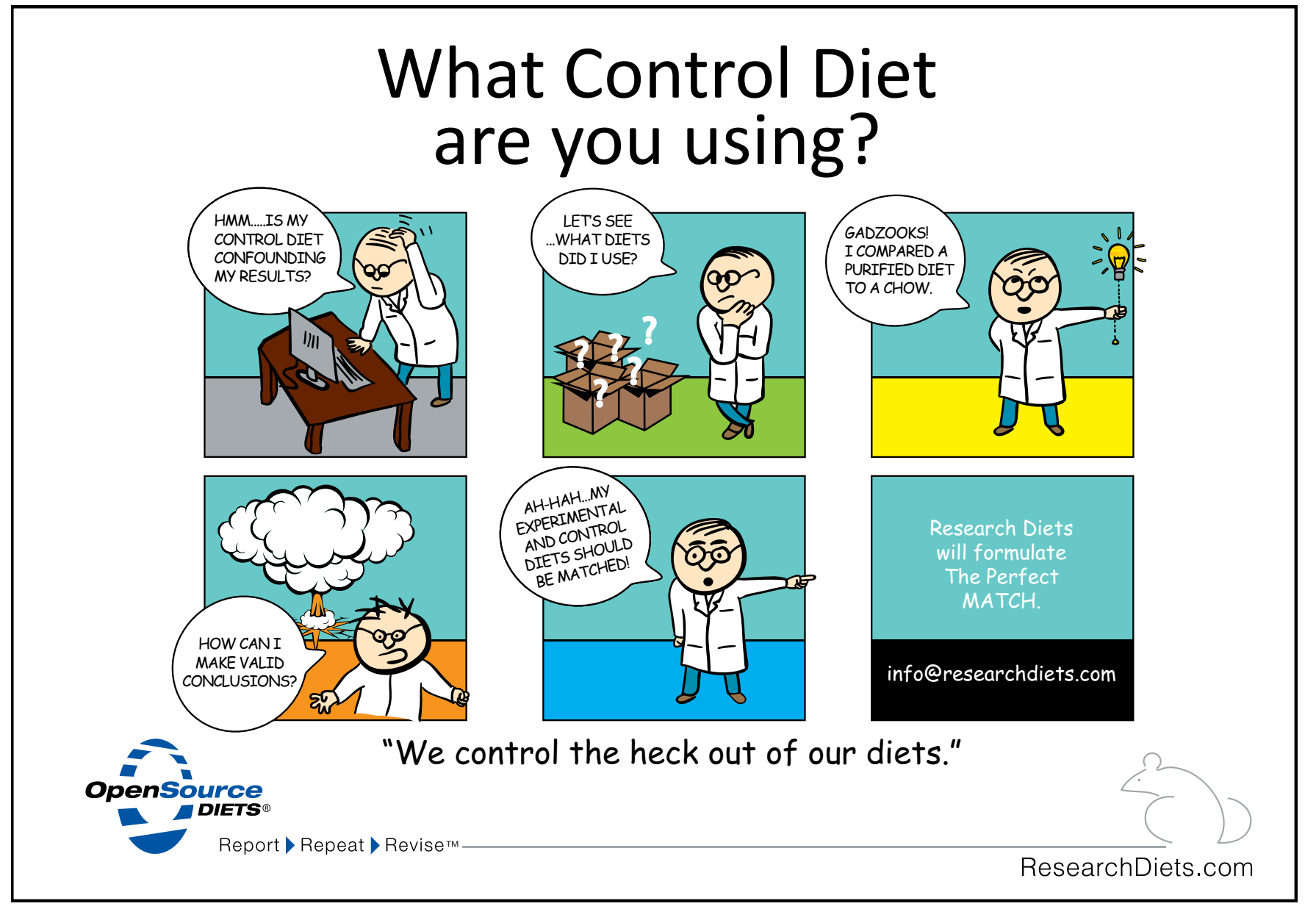

